\title{
Axonal Regulation of Myelin Protein mRNA Levels in Actively Myelinating Schwann Cells
}

\author{
Bruce D. Trapp, Peter Hauer, and Greg Lemke' \\ The Johns Hopkins University School of Medicine, Department of Neurology, Neuromuscular Division, Baltimore, Maryland \\ 21205, and 'Molecular Neurobiology Laboratory, The Salk Institute, San Diego, California 92138
}

\begin{abstract}
Upon transection of a peripheral nerve, axons distal to the transection degenerate. As a consequence of this axonal degeneration, myelin-forming Schwann cells cease biosynthesis of new myelin membrane, contribute to phagocytosis of previously formed myelin, and markedly down-regulate expression of myelin-specific markers. Among the most prominent of these down-regulated markers are the major structural proteins of peripheral myelin, $P_{0}$ and myelin basic protein (MBP). We have used slot blot and in situ hybridization techniques to demonstrate that for actively myelinating Schwann cells, down-regulation of the $P_{0}$ and MBP genes occurs primarily at the level of mRNA expression. Together with other recent data, these findings strongly argue for axonal modulation of $P_{0}$ and MBP gene transcription during active myelination.
\end{abstract}

Schwann cells of the PNS can be divided into 2 distinct cell types, those that ensheathe multiple axons and those that tightly and repeatedly wrap a single axon, resulting in formation of the myelin sheath (Raine, 1984; Webster and Favilla, 1984). Although all Schwann cells have the potential to form this sheath, they will do so only upon induction by appropriate peripheral axons (Aguayo et al., 1976; Weinberg and Spencer, 1976; Bray et al., 1981). A key feature of this axon-mediated induction is the activation and high-level expression of the genes encoding the major myelin proteins $P_{\mathrm{O}}$ and myclin basic protcin (MBP) (Lemke, 1986).

$\mathrm{P}_{\mathrm{o}}$ and MBP accumulate to very high levels during postnatal development, with a time course that closely parallels the rate of myelin production in peripheral nerve (Wood and Engel, 1976; Lemke and Axel, 1985; Willison et al., 1987). Schwann cells that do not elaborate myelin, however, do not express significant amounts of these proteins (Brockes et al., 1979; Trapp et al., 1981, 1987; Willison et al., 1988). Previous studies have also indicated that maintenance of the myelin sheath depends on survival of myelinated axons. When myelinated axons degenerate, for example, both myelin synthesis and expression of

\footnotetext{
Received Dec. 10, 1987; revised Jan. 29, 1988; accepted Feb. 2, 1988.

We thank Dr. John Griffin for critical review of the manuscript, Cindi Cootauco for technical assistance, and Rod Graham for typing and editing the manuscript This work was supported by Grants NS 22849 (B.D.T.) and NS 23896 (G.L.) from the NIH and Grant RG 1844 (G.L.) from the National Multiple Sclerosis Society.

B.D.T. is a Harry Weaver Neurosciences Scholar of the National Multiple Sclerosis Socicty; G.L. is an awardec of the Pew Scholars Program in the Biomedical Sciences.

Correspondence should be addressed to Bruce D. Trapp, The Johns Hopkins University School of Medicine, 600 North Wolfe Street, Meyer 6-181, Baltimore, MD 21205.

Copyright @ 1988 Society for Neuroscience $0270-6474 / 88 / 093515-07 \$ 02.00 / 0$
}

the major myelin proteins are dramatically reduced (Mirsky et al., 1980; Politis et al., 1982; Poduslo et al., 1984; Willison et al., 1988). These and related data have been interpreted as indicating that axons induce and regulate myelin gene expression during formation and maintenance of the myelin sheath.

We have tested this hypothesis directly. Rat sciatic nerves were transected during a period of active myelination, and the level and distribution of $\mathrm{P}_{\mathrm{o}}$ and $\mathrm{MBP}$ mRNAs were determined in denervated regions distal to the site of transection. We find a 40-fold decrease in the level of these messages at $5 \mathrm{~d}$ posttransection. In situ hybridization studies demonstrate that this decrease occurs simultaneously along the entire distal stump. These data indicate that axons regulate myelination at the level of Schwann cell mRNA expression, most probably through direct modulation of transcription.

\section{Materials and Methods}

Tissues. Sixteen 35-d-old Sprague-Dawley rats were used for morphological studies. Under appropriate anesthetic, the right sciatic nerve was transected above the sciatic notch in 8 of the rats. The proximal stump and attached L4 and L5 roots were removed to prevent reinnervation of the distal stump which remained in its normal orientation so that various regions could be analyzed. At $2,5,10$, and $20 \mathrm{~d}$ posttransection, 2 normal rats and 2 rats having right sciatic nerve transections were perfused with $4 \%$ paraformaldehyde in $0.08 \mathrm{~m}$ phosphate buffer. The distal stumps and the left sciatic nerves were removed from transected animals, and the right sciatic nerve was removed from control animals. These nerves were dissected into 3 equal segments (proximal, mid, and distal), placed in fixative overnight and then processed to paraffin by standard procedures. Two paraffin blocks were produced for each time point. Both contained the transected distal stump, the untransected left sciatic nerve, and the right sciatic nerve from a control animal. Sections were cut at a thickness of $6 \mu \mathrm{m}$, placed on glass slides, deparaffinized, and rehydrated prior to use. In situ hybridization and immunohistochemistry were performed separately on adjacently cut sections.

Fifty 35-d-old Sprague-Dawley rats were used for hiochemical studies. Under appropriate anesthetic, both sciatic nerves were transected above the sciatic notch in 25 of the animals. The proximal end of each distal stump was sutured into the musculature at the inferior aspect of the thigh. At 1, 2, 5, 10, and $20 \mathrm{~d}$ after transection, the distal stumps from 5 animals and the sciatic nerves from 5 control animals were removed and stored in liquid nitrogen prior to RNA isolation.

In situ hybridization. Sections on slides were prehybridized and hybridized as described previously (Trapp et al., 1987). Probes were ${ }^{33} \mathrm{~S}$-labeled nick-translated $\mathrm{P}_{\mathrm{O}}$ and $\mathrm{MBP}$ cDNAs. Autoradiography was performed by standard procedures. Following development of the emulsion, sections were stained with hematoxylin, dehydrated, and overlaid with coverslips. Sections were photographed with a Zeiss Axiophat microscope under both bright and dark fields. The $P_{0}$ and MBP cDNA clones used have been characterized and described elsewhere (Roach et al., 1983; Lemke and Axel, 1985).

Immunohistochemistry. Sections were stained with a well-characterized $\mathrm{P}_{\mathrm{O}}$ antiserum (Trapp et al., 1979) by the peroxidase-antiperoxidase procedure as described previously (Trapp et al., 1981).

RNA isolation and analysis. Total RNA was extracted from frozen 

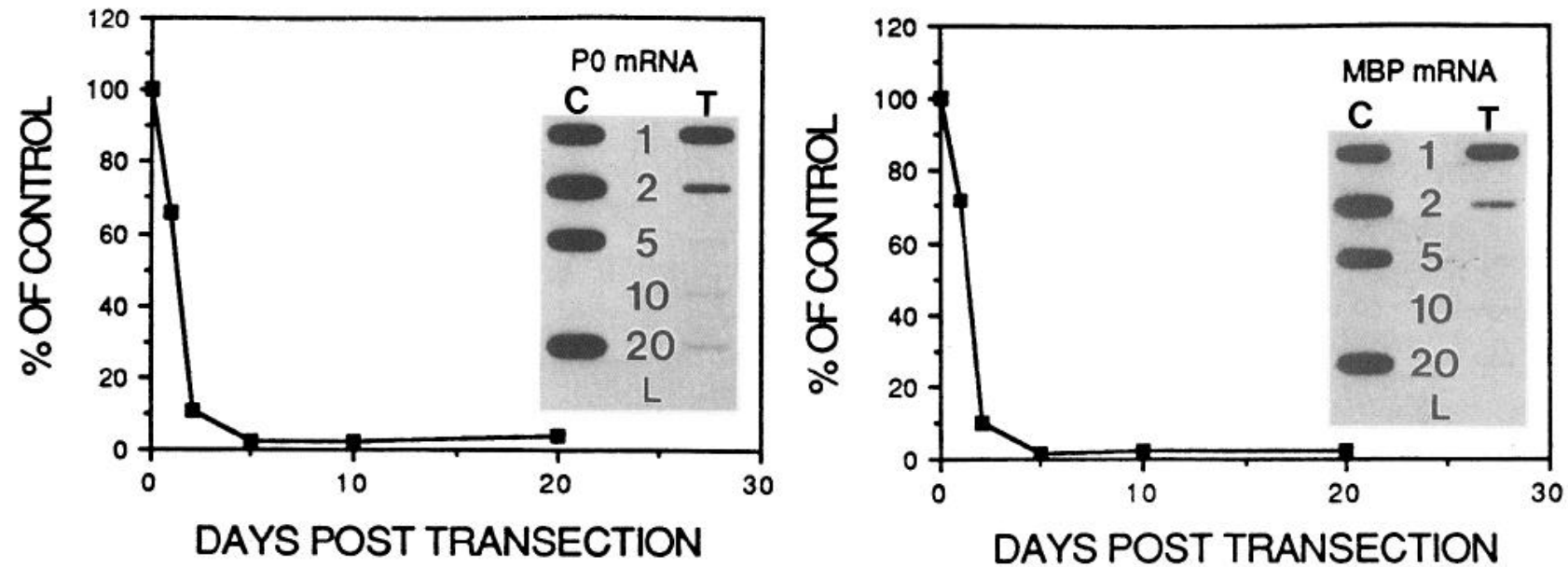

Figure 1. Slot blot determination of major myelin RNA levels in control and transected rat sciatic nerves. Total cellular RNA (1 $\mu \mathrm{g})$ from control $(C)$ or transected $(T)$ rat sciatic nerves and from rat liver $(L)$ was immobilized to a nylon support and hybridized at high stringency to ${ }^{32} \mathrm{P}$-radiolabeled $\mathrm{P}_{\mathrm{O}}$ (left) and MBP (right) cDNA clones. Numbers on blots refer to days posttransection; a day 10 posttransection control point was not taken. Exposure time for the $\mathrm{P}_{\mathrm{O}}$ blot was $12 \mathrm{hr}$ with an intensifying screen; for the MBP blot, $24 \mathrm{hr}$ with an intensifying screen. Each blot autoradiogram was scanned with a densitometer, and percentage control values were calculated by dividing the integrated hybridization signal from each experimental (transected) point by the average of the hybridization signal for the 4 control points. Autoradiography was performed at $-70^{\circ} \mathrm{C}$ using preflashed X-ray film.

tissue by homogenization in guanidine thiocyanate and subsequent precipitation with lithium chloride as described by Cathala et al. (1983). Then, $0.4,1$, and $2 \mu \mathrm{g}$ of total RNA from transected and control sciatic nerves and from liver were denatured in $6 \times \mathrm{SSC} / 7.4 \%$ formaldehyde and immobilized to GeneScreen (New England Nuclear) using a slot blotter (Schleicher and Schuell). Slot blots were hybridized and washed at high stringency using nick-translated ${ }^{32} \mathrm{P}$-labeled $\mathrm{cDNA}\left(\mathrm{P}_{\mathrm{O}}\right.$ and $\left.\mathrm{MBP}\right)$ probes as described previously (Lemke and Axel, 1985).
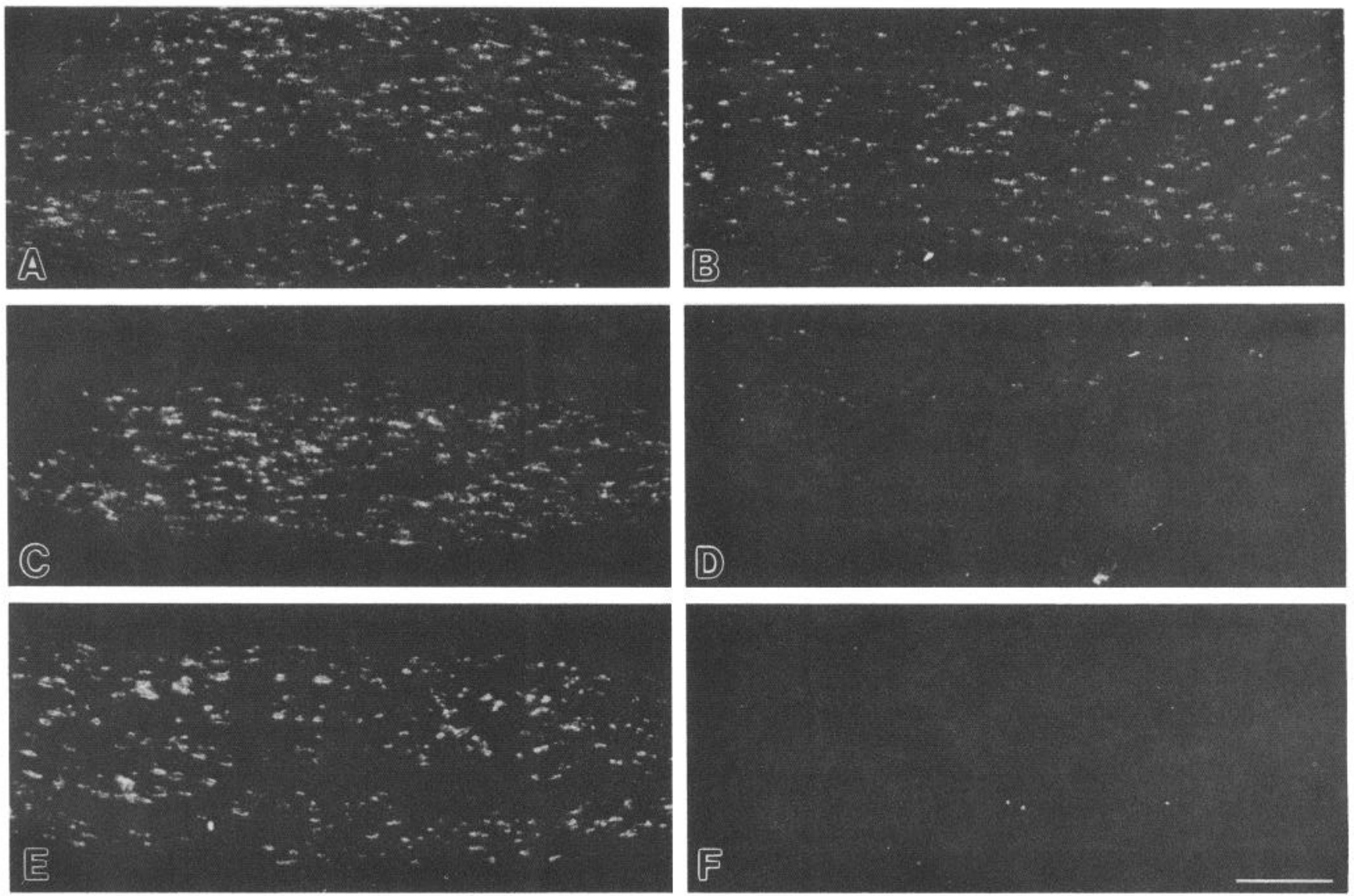

Figure 2. Comparison of the distribution of $\mathrm{P}_{\mathrm{O}}$ mRNA in longitudinally oriented paraffin sections of aged-matched control $(A, C, E)$ and $2(B), 5$ $(D)$, and $20 \mathrm{~d}(F)$ transected rat sciatic nerves. Clusters of $\mathrm{P}_{\mathrm{O}}$ mRNA were readily detectable in all control sections. The general distribution of $\mathrm{P}_{\mathrm{O}}$ mRNA $2 \mathrm{~d}$ after transection was similar to controls. $\mathrm{P}_{\mathrm{O}}$ mRNA clusters were reduced dramatically $5 \mathrm{~d}$ after transection and were not detected in $20 \mathrm{~d}$ transected nerves. Dark-field optics. Scale bar, $75 \mu \mathrm{m}$. 


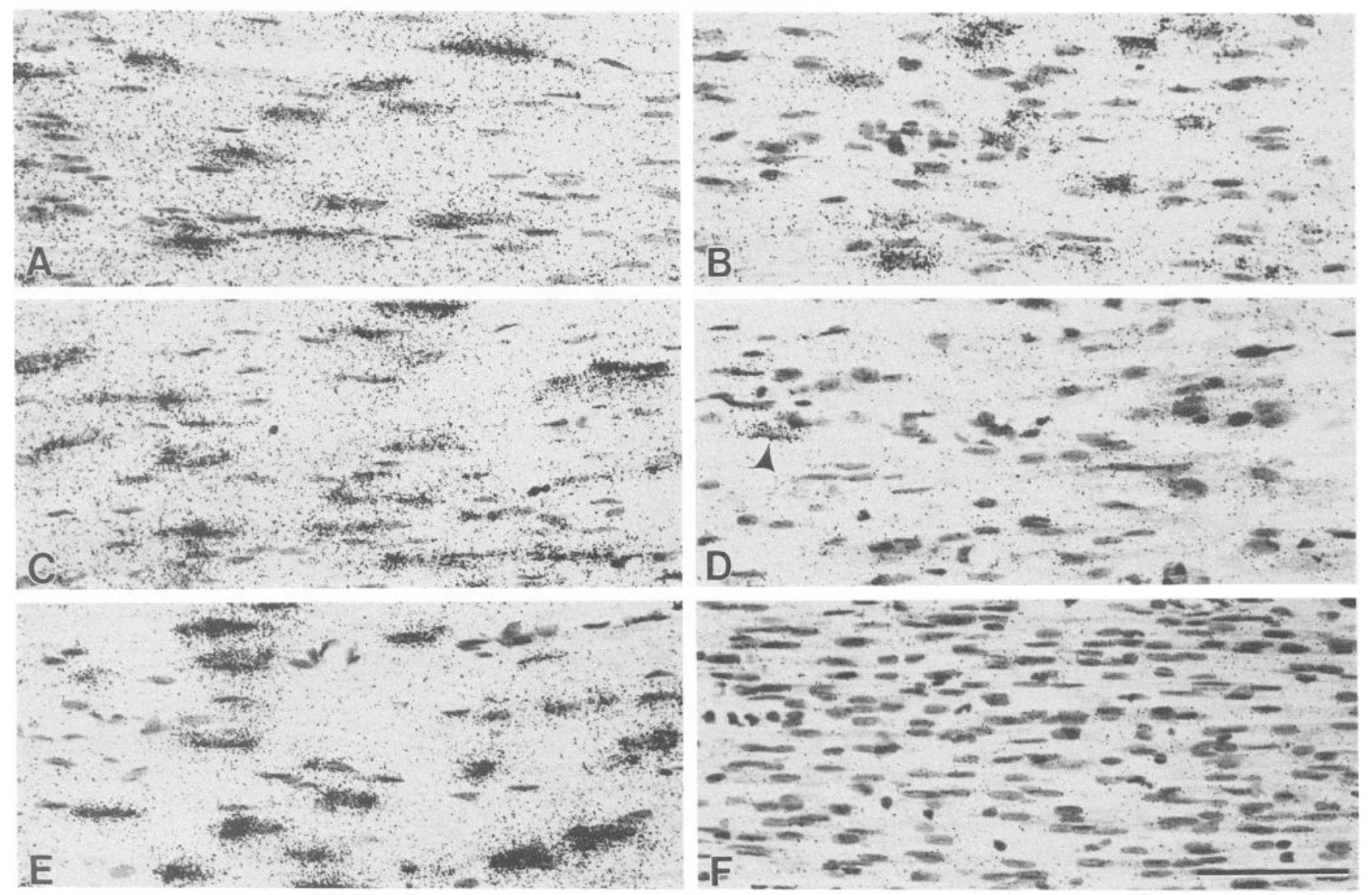

Figure 3. Bright-field analysis of sections in Figure 2. Clusters of silver grains representing $\mathrm{P}_{\mathrm{O}} \mathrm{mRNA}$ were concentrated around Schwann cell nuclei in control sections $(A, C, E)$. Smaller $\mathrm{P}_{\mathrm{O}}$ mRNA clusters containing few silver grains surrounded Schwann cell nuclei $2 \mathrm{~d}$ after transection $(B)$. Perinuclear concentrations of $\mathrm{P}_{\mathrm{O}}$ mRNA were rarely found $5 \mathrm{~d}$ after transcription $(D$, arrowhead $)$ and were not detected in sections from 20 d posttransected nerves $(F)$. A dramatic increase in the number of cell nuclei per unit area of nerve occurred between 5 and $20 \mathrm{~d}$ after transection. Scale bar, $30 \mu \mathrm{m}$.

\section{Results}

Myelin RNA levels in transected sciatic nerves

We extracted total cellular RNA from normal sciatic nerves and from the distal stumps of transected nerves at 1, 2, 5, 10, and $20 \mathrm{~d}$ posttransection. The relative levels of $\mathrm{P}_{\mathrm{O}}$ and MBP transcripts present in each of these RNA preparations were then determined by Northern and slot blot hybridizations. Slot blots were performed using 3 different amounts of RNA in order to quantitate changes in myelin transcript levels accurately. The results of these studies (Fig. 1) indicate that transection causes a dramatic reduction in the steady-state level of $\mathrm{P}_{\mathrm{O}}$ and MBP RNAs: These transcripts were each reduced approximately 40 fold by $5 \mathrm{~d}$ posttransection. Although the kinetics of this reduction were similar for the 2 genes, MBP message levels fell slightly faster than those for $\mathrm{P}_{\mathrm{O}}$. Both the $\mathrm{P}_{\mathrm{O}}$ and MBP RNAs are reduced by $1 \mathrm{~d}$ posttransection, with maximal reduction observed by $5 \mathrm{~d}$ after the operation. Both messages also showed a very slight but consistent increase between 5 and 20 d posttransection. Analysis of Northern blot hybridizations indicated no change in the size of $\mathrm{P}_{\mathrm{O}}$ or MBP transcripts following transection (data not shown).

\section{In situ hybridization}

In order to assess axonal effects on glial gene expression at the cellular level, we used in situ hybridization to examine the dis- tribution of $\mathrm{P}_{\mathrm{O}}$ and MBP mRNAs in tissue sections of $2,5,10$, and $20 \mathrm{~d}$ transected distal stumps and compared this distribution to that found in age-matched control nerves. For each time point, sections of control and transected nerves were hybridized on the same slide. The relative intensities of hybridization signals in normal and transected nerves were thereby internally controlled. The general distribution of $\mathrm{P}_{\mathrm{O}}$ and MBP mRNAs was analyzed in dark-field images (Figs. 2 and 4); more precise localization of these mRNAs was obtained in bright-field images photographed at higher magnification (Figs. 3 and 5).

$\mathrm{P}_{\mathrm{O}}$ message was readily detected in control nerves at all ages studied (Fig. 2). Silver grains resulting from cDNA-mRNA hybridization appeared in clusters that were distributed throughout these sections. The general distribution of $P_{O}$ mRNA in sections of $2 \mathrm{~d}$ distal stumps was similar to that found in control nerves. In sections from $5 \mathrm{~d}$ distal stumps, however, $\mathrm{P}_{\mathrm{O}}$ message clusters were rare and less intense than those found in control nerves. These message clusters were not detected in 10 and 20 d distal stumps (Fig. 2).

When analyzed under bright-field optics, silver grains representing $\mathrm{P}_{\mathrm{O}}$ message were concentrated around Schwann cell nuclei in sections from control nerves (Fig. 3). The hybridization apparent in dark-field images of $2 \mathrm{~d}$ transected nerves was also located around Schwann cell nuclei. Compared with age-matched control nerves, the number of silver grains in the $2 \mathrm{~d}$ transected nerves was significantly reduced. Only occasional nuclei were 

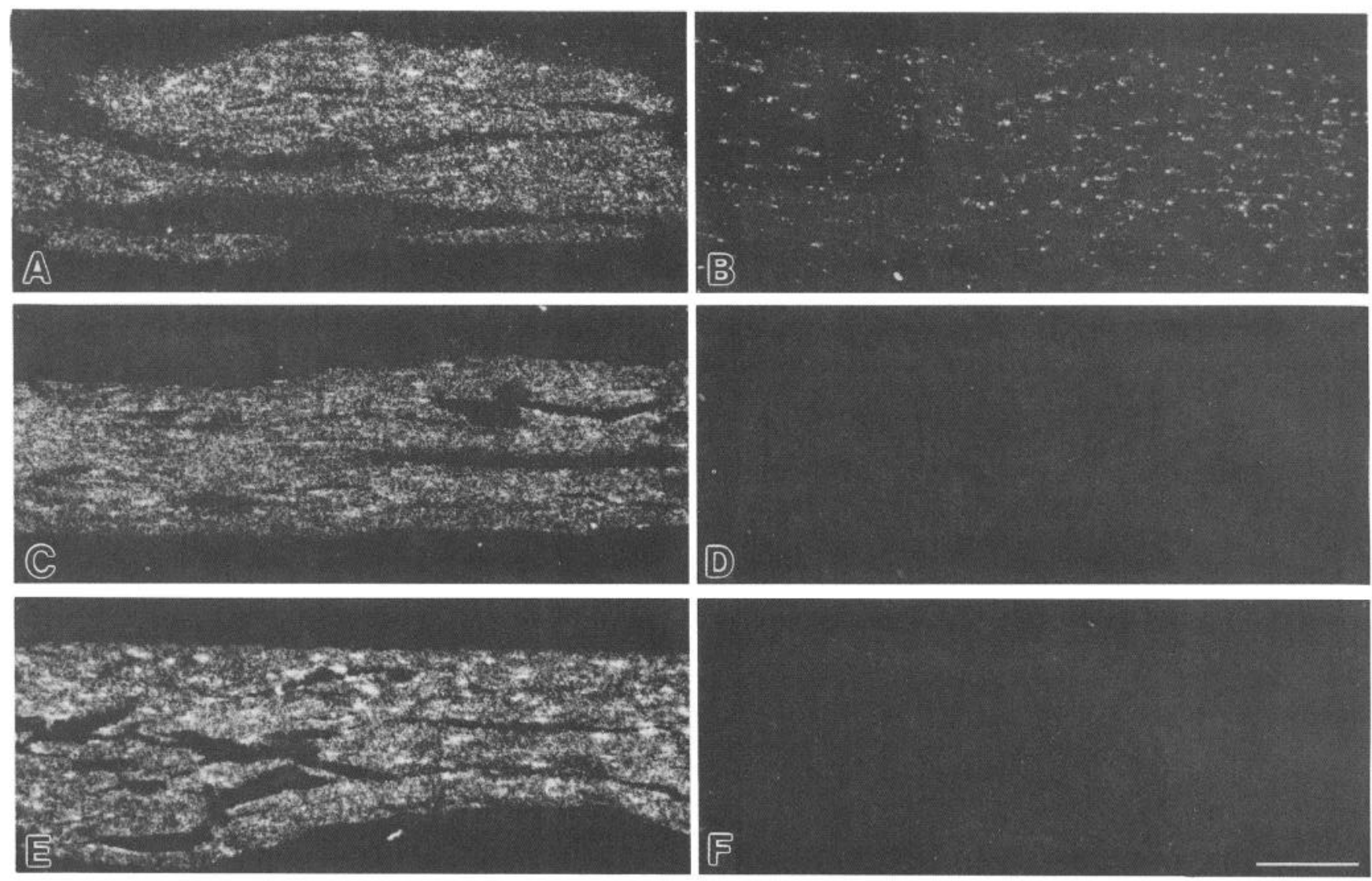

Figure 4. Comparison of the distribution of MBP mRNA in longitudinally oriented paraffin sections of age-matched control $(A, C, E)$ and $2(B)$, $5(D)$, and $20 \mathrm{~d}(F)$ transected rat sciatic nerves. MBP mRNA was distributed diffusely throughout all control sections and was localized in small clusters $2 \mathrm{~d}$ after transection. MBP message was not detected in sections from 5 and $20 \mathrm{~d}$ transected nerves. Dark-field images. Scale bar, $75 \mu \mathrm{m}$.

surrounded by concentrations of silver grains in sections from $5 \mathrm{~d}$ transected nerves. The number of these grains was dramatically reduced compared with age-matched controls, consistent with the data we obtained from slot blot hybridizations. The distribution of Schwann cell nuclei in 2 and $5 \mathrm{~d}$ transected nerves did not differ significantly from controls, although, as expected, a significant increase in the density of nuclei was observed in 10 and $20 \mathrm{~d}$ transected nerves. While silver grains were diffusely scattered throughout these 10 and $20 \mathrm{~d}$ sections at a low level, concentrations of grains were never observed around cell nuclei.

MBP mRNA was also readily detected in sections of control nerves at all ages studied (Fig. 4). In contrast to $P_{O}$ message, however, MBP mRNA was distributed more diffusely over myelinated fibers. This diffuse distribution was reduced by $2 \mathrm{~d}$ posttransection: occasional, randomly distributed foci of MBP hybridization were observed. MBP message was not detectable in dark-field images of sections from 5, 10, and $20 \mathrm{~d}$ transected nerves. When analyzed with bright-field optics, the majority of silver grains corresponding to MBP mRNA were diffusely scattered throughout myelinated fibers, although occasional clusters of grains were apparent. These clusters were smaller and much less intense than those found in sections hybridized with $P_{O}$ probes and were not consistently associated with Schwann cell nuclei (Fig. 5). Few silver grains were observed over sections from 5, 10, and $20 \mathrm{~d}$ transected nerves.

\section{Immunocytochemistry}

Myelin sheaths in control nerves from all time points were stained intensely by $\mathrm{P}_{\mathrm{O}}$ antiserum. The distribution of $\mathrm{P}_{\mathrm{O}}$ protein in sections of $2 \mathrm{~d}$ distal stumps was similar to the distribution found in control nerves. However, in sections of $5 \mathrm{~d}$ distal stumps, $\mathrm{P}_{\mathrm{O}}$ antiserum stained discontinuous ovoids, which are a hallmark of the early stages of Wallerian degeneration. The size and number of these $\mathrm{P}_{\mathrm{O}}$-positive ovoids were decreased in sections of $10 \mathrm{~d}$ distal stumps. Since our Northern and slot blot analysis showed a small increase in $\mathrm{P}_{\mathrm{O}}$ and MBP mRNA levels between 5 and $20 \mathrm{~d}$ posttransection, $\mathrm{P}_{\mathrm{O}}$-stained sections of 20 d distal stumps were examined for evidence of remyelination (Fig. 6). Although $\mathrm{P}_{\mathrm{O}}$ immunoreactivity was present in these sections, it was restricted to myelin debris that had not been removed. No evidence of remyelination was found.

\section{Discussion}

Schwann cells exhibit remarkable phenotypic plasticity, which is largely controlled through their association with various types of axons (Aguayo et al., 1976; Spencer et al., 1979; Mirsky et al., 1980; Politis et al., 1982). The primary metabolic level at which this control is exercised, however, has not been firmly established. Recent transection studies, performed with adult nerves in which myelination is essentially complete, have been taken to suggest that axonal influences may be mediated at 


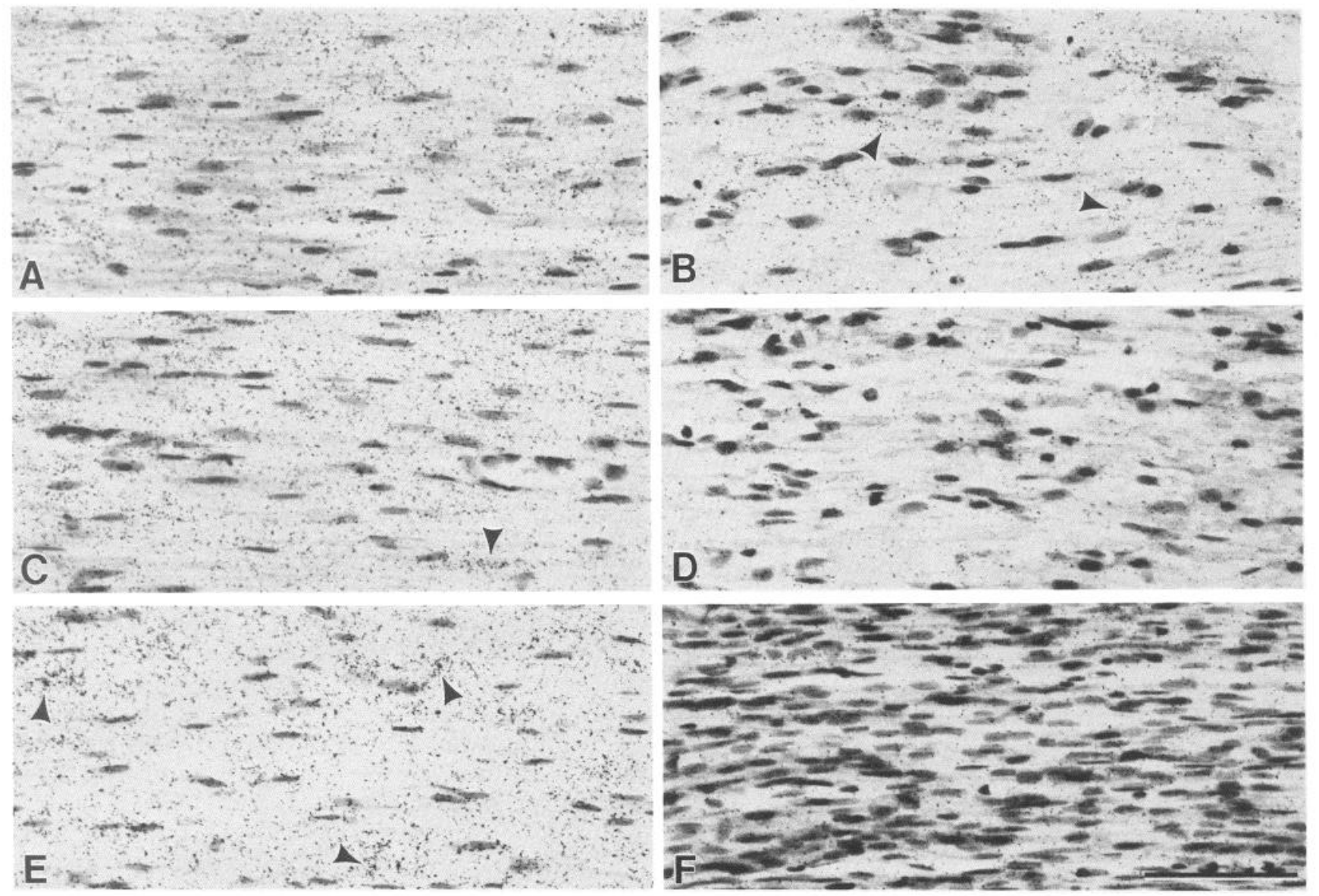

Figure 5. Bright-field analysis of sections in Figure 4. Silver grains representing MBP message are distributed diffusely in control sections ( $A$, $C$, $E$ ). Small clusters of silver grains, not always associated with cell nuclei (arrowheads) were also present in control and $2 \mathrm{~d}$ transected nerves $(B)$. Few silver grains were present at $5(D)$ and $20(F)$ d after transection. Scale bar, $30 \mu \mathrm{m}$.

transcriptional, posttranscriptional, translational, and/or protein processing levels (Poduslo et al., 1985; Brunden and Poduslo, 1987; LeBlanc et al., 1987). Our data clearly indicate that during active myelination, axons regulate Schwann cell phenotype primarily at the level of mRNA expression. For reasons discussed below, this regulation is likely to be mediated directly through changes in gene transcription.

Our quantitative slot blot analyses (Fig. 1) demonstrate that $\mathrm{P}_{\mathrm{O}}$ and MBP mRNA levels in distal stumps are reduced by similar degrees at $1 \mathrm{~d}$ (3-fold), $2 \mathrm{~d}$ (9-fold), and $5 \mathrm{~d}$ (40-fold) after nerve transection. These data indicate that major myelin message levels are reduced by axon withdrawal, just as they are induced during postnatal development (Lemke and Axel, 1985; Lemke, 1986). Our in situ hybridization studies confirm the extent and time course of the reduction of these mRNAs and provide additional information about their cellular and subcellular distribution. For example, although reduced by $90 \%$, the general distribution of $\mathrm{P}_{\mathrm{o}}$ message in sections from $2 \mathrm{~d}$ distal stumps did not differ significantly from control nerves: The number of Schwann cells expressing detectable levels of mRNA was similar, although the number of silver grains surrounding individual cells was substantially reduced. These results suggest that $P_{O}$ message levels are down-regulated generally in all myelin-forming Schwann cells, rather than differentially in a select subpopulation. Those cells situated close to the site of transec- tion, for example, lose $\mathrm{P}_{\mathrm{o}}$ mRNA expression over a time course similar to that of cells located more distally.

MBP mRNA was distributed diffusely over myelinated fibers in control sections. This diffuse distribution reflects the translocation of MBP mRNA from Schwann cell perinuclear regions to cytoplasmic domains along the myelin internode and is consistent with translation of this message near the sites of MBP insertion into compact myelin (Trapp et al., 1987). This distribution is markedly different from the perinuclear localization of $P_{O}$ mRNA. This difference almost certainly reflects the different translational modes used for these 2 messages: $P_{o}$ mRNA encodes an integral membrane protein that is translated on membrane-bound polysomes (rough ER) localized near the Schwann cell nucleus (Trapp et al., 1987), while MBP mRNA encodes a soluble, extrinsic membrane protein that is translated on free ribosomes (Colman et al., 1982).

The distribution of MBP mRNA in $2 \mathrm{~d}$ distal stumps differed from control nerves in that silver grains often appeared in clusters that were evenly distributed along the length of the distal stump. This hybridization pattern is suggestive of a general down-regulation of MBP message levels as well as altered MBP mRNA transport along each myelin internode. In contrast to $\mathrm{P}_{\mathrm{O}}$ mRNA, the MBP message clusters in $2 \mathrm{~d}$ transected nerves often had no apparent association with Schwann cell nuclei.

Significant levels of MBP mRNA could not be detected by in 


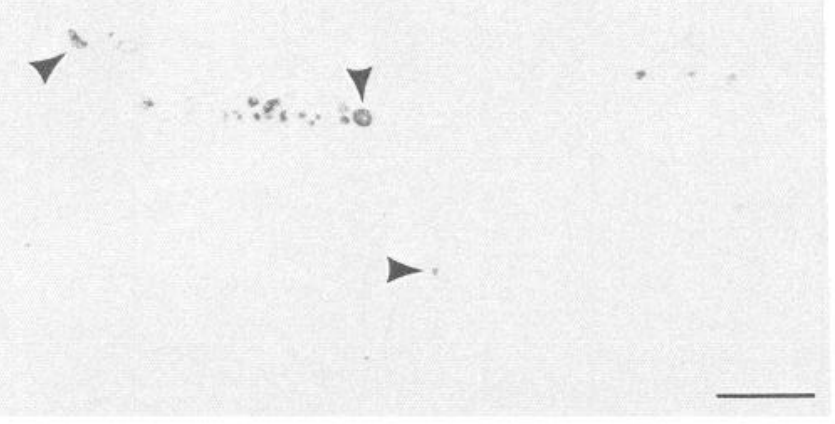

Figure 6. Paraffin section of $20 \mathrm{~d}$ transected nerve oriented longitudinally and immunostained with $\mathrm{P}_{\mathrm{O}}$ antibodies. Detectable $\mathrm{P}_{\mathrm{O}}$ protein is restricted to myelin debris (arrowheads). No evidence of remyelination was found. Scale bar, $40 \mu \mathrm{m}$.

situ hybridization to tissue sections of $5 \mathrm{~d}$ distal stumps, although small clusters of $P_{O}$ message surrounding an occasional Schwann cell nucleus were still observed (Figs. 2-5). Our inability to detect MBP message by in situ hybridization to these sections probably results from both the lower absolute concentration of this mRNA (relative to $\mathrm{P}_{\mathrm{O}}$ ) and its diffuse distribution within Schwann cells. The density of Schwann cells increased dramatically between 5 and 20 d posttransection. Although this increase in cell density was accompanied by a slight increase in major myelin message levels as determined by slot blot hybridization (Fig. 1), neither $\mathrm{P}_{\mathrm{O}}$ nor MBP mRNA was detected by in situ hybridization to sections from 10 and $20 \mathrm{~d}$ nerves. These observations support the hypothesis that in 10 and $20 \mathrm{~d}$ distal stumps major myelin mRNAs are present at low concentrations in many cells rather than at high concentrations in restricted populations.

Taken together, our data clearly demonstrate that during a period of active myelination, axonal regulation of Schwann cell phenotype is primarily effected through modulation of Schwann cell mRNA levels. This hypothesis is supported by a series of experiments recently performed with purified neonatal Schwann cells cultured in vitro in the absence of axons. When dissociated from the neonatal nerve at a time of rapid myelination and placed into culture, these cells cease myelin synthesis and markedly down-regulate expression of the major myelin proteins (Mirsky et al., 1980). Lemke and Chao (1988) have observed that this "dedifferentiation" is accompanied by a corresponding 40-fold down-regulation in the level of $\mathrm{P}_{\mathrm{O}}$ and MBP mRNAs over $5 \mathrm{~d}$ in culture. The magnitude and time course of this reduction are in remarkably good agreement with the in vivo data described above. That these changes directly reflect modulation of myelin gene transcription can be inferred from 2 additional observations. Lemke and Chao (1988) have shown that the low levels of $\mathrm{P}_{\mathrm{O}}$ and MBP mRNAs expressed by Schwann cells cultured in the absence of axons can be markedly elevated by forskolin-induced increases in intracellular cyclic AMP. This second messenger has, in turn, been demonstrated to strongly potentiate the transcriptional activity of the cloned promoter region of the rat $\mathrm{P}_{\mathrm{O}}$ gene: This promoter, when linked to a heterologous reporter enzyme and transfected into cultured Schwann cells, is active only when these cells are grown in the presence of an agent that elevates intracellular cAMP (Lemke et al., 1988). Cyclic AMP, therefore, should be considered as a potential mediator of axonal influences on myelin gene expression in vivo.

Recent studies examining the effects of permanent transection of adult sciatic nerves on Schwann expression of $\mathrm{P}_{\mathrm{O}}$ protein have been reported to result in a modest (3-fold) decrease in $\mathrm{P}_{\mathrm{O}}$ mRNA levels (LeBlanc et al., 1987), an alteration of the glycosylation pattern of the $\mathrm{P}_{\mathrm{O}}$ protein (Poduslo, 1985), and an augmentation of the rate at which this protein is delivered to lysosomes (Brunden and Poduslo, 1987). Thus, these studies have been alternatively interpreted as indicating that axonal effects can be mediated at transcriptional, posttranscriptional, protein processing, and protein sorting steps. Which of these regulatory control points is paramount during normal Schwann cell differentiation has proven difficult to assess, largely because in the adult, Schwann cell differentiation and myelination are essentially complete and the major myelin RNAs have consequently fallen to low relative levels (Lemke and Axel, 1985; LeBlanc et al., 1987).

In contrast, the studies described in this report involve analysis of axonal regulation in the sciatic nerves of 35-d-old rats, a time at which the rate of myelin deposition is just below the peak levels observed around postnatal day 21 . Similarly, the in vitro studies of Lemke and Chao (1988) involve analysis of cells dissociated from 2-3 d sciatic nerve, a time at which the rate of myelin formation is also very high. The congruence of the data obtained from these 2 independent approaches strongly suggests that axons regulate Schwann differentiation primarily at the level of gene expression, probably through direct modulation of transcription. It should be emphasized that this modulation is not always positive, however. Nerve growth factor receptors (Taniuchi et al., 1986) and NGF receptor mRNA (Lemke and Chao, 1988) have recently been shown to increase dramatically upon withdrawal of axons, a finding that indicates that axons are capable of both positive and negative regulation of Schwann cell gene expression. The availability of cloned probes for the major myelin and NGF receptor genes should now allow us to investigate this regulatory capability directly.

\section{References}

Aguayo, A. J., L. Charron, and G. M. Bray (1976) Potential of Schwann cells from unmyelinated nerves to produce myelin: A quantitative ultrastructural and autoradiographic study. J. Neurocytol. 5: 565573.

Bray, G. M., M. Rasminsky, and A. J. Aguayo (1981) Interactions between axons and their sheath cells. Annu. Rev. Neurosci. 4: 127162.

Brockes, J. P., M. C. Raff, D. J. Nishiguchi, and J. Winter (1979) Studies on cultured rat Schwann cells. III. Assays for peripheral myelin proteins. J. Neurocytol. 9: 67-77.

Brunden, K. R., and J. F. Poduslo (1987) Lysosomal delivery of the major myelin glycoprotein in the absence of myelin assembly. J. Cell Biol. 104: 661-669.

Cathala, G., J.-F. Savouret, B. Mendez, B. L. West, M. Karin, J. A. Martial, and J. D. Baxter (1983) A method for isolation of intact, translationally active ribonucleic acid. DNA 2: 329-335.

Colman, D. R., G. Kreibich, A. B. Frey, and D. D. Sabatini (1982) Synthesis and incorporation of myelin polypeptides into CNS myelin. J. Cell Biol. 95: 598-608.

LeBlanc, A. C., J. F. Poduslo, and C. Mezei (1987) Gene expression in the presence or absence of myelin assembly. Mol. Brain Res. 2: $57-67$.

Lemke, G. (1986) Molecular biology of the major myelingenes. Trends Neurosci. 9: 266-270.

Lemke, G., and R. Axel (1985) Isolation and sequence of a cDNA encoding the major structural protein of peripheral myelin. Cell 40 : 501-508. 
Lemke, G., and M. C. Chao (1988) Axons regulate Schwann cell expression of the major myelin and NGF receptor genes. Development 102: 499-504.

Lemke, G., E. Lamar, and J. Patterson (1988) Isolation and analysis of the gene encoding peripheral myelin protein zero. Neuron $1: 73-$ 83.

Mirsky, R., J. Winter, E. R. Abney, R. M. Pruss, J. Gavrilovic, and M. C. Raff (1980) Myelin-specific proteins and glycolipids in rat Schwann cells and oligodendrocytes in culture. J. Cell Biol. 84: 483-494.

Poduslo, J. F. (1985) Posttranslational protein modification: Biosynthetic control mechanisms in the glycosylation of the major myelin glycoprotein by Schwann cells. J. Neurochem. 44: 1194-1206.

Poduslo, J. F., C. T. Berg, and P. J. Dyck (1984) Schwann cell expression of a major myelin glycoprotein in the absence of myelin assembly. Proc. Natl. Acad. Sci. USA 81: 1864-1866.

Poduslo, J. F., P. J. Dyck, and C. T. Berg (1985) Regulation of myelination. J. Neurochem. 44: 388-400.

Politis, M. J., N. Sternberger, K. Ederle, and P. S. Spencer (1982) Studies on the control of myelinogenesis. J. Neurosci. 2: 1252-1266.

Raine, C. S. (1984) Morphology of myelin and myelination. In Myelin, 2nd ed., P. Morell, ed., pp. 1-50, Plenum, New York.

Roach, A., K. Boylan, S. Horvath, S. B. Prusiner, and L. E. Hood (1983) Characterization of a cloned cDNA representing rat myelin basic protein. Cell 34: 799-806.

Spencer, P. S., H. J. Weinberg, V. Krygier-Brevart, and V. Zabrenetsky (1979) An in vivo method to prepare normal Schwann cells free of axons and myelin. Brain Res. 165: 119-126.

Taniuchi, M., H. B. Clark, and E. M. Johnson, Jr. (1986) Induction of nerve growth factor receptors in Schwann cells after axotomy. Proc. Natl. Acad. Sci. USA 83: 4094-4098.
Trapp, B. D., L. J. McIntyre, R. H. Quarles, N. H. Sternberger, and H. deF. Webster (1979) Immunocytochemical localization of rat peripheral nervous system proteins: $P_{2}$ protein is not a component of all peripheral nervous system myelin sheaths. Proc. Natl. $\Lambda$ cad. Sci. USA 76: 3552-3556.

Trapp, B. D., Y. Itoyama, N. H. Sternberger, R. H. Quarles, and H. deF. Webster (1981) Immunocytochemical localization of $\mathbf{P}_{\mathrm{o}}$ protein in Golgi complex membranes and myelin of developing rat Schwann cells. J. Cell Biol. 90: 1-6.

Trapp, B. D., T. Moench, M. Pulley, E. Barbosa, E. Tennekoon, and J. Griffin (1987) Spatial segregation of mRNA encoding myelin-specific proteins. Proc. Natl. Acad. Sci. USA 84: 7773-7777.

Webster, H. deF., and J. T. Favilla (1984) Development of peripheral nerve fibers. In Peripheral Neuropathy, P. J. Dyck, P. K. Thomas, E. H. Lambert, and R. Bunge, eds., pp. 329-359, W. B. Saunders, Philadelphia.

Weinberg, H. J., and P. S. Spencer (1976) Studies on the control of myelinogenesis. II. Evidence for neuronal regulation of myelin production. Brain Res. 113: 363-378.

Willison, H. J., A. I. Ilyas, D. J. O'Shannessy, M. J. Pulley, B. D. Trapp, and R. H. Quarles (1987) Myelin-associated glycoprotein and related glycoconjugates in developing cat peripheral nerve: A correlative biochemical and morphometric study. J. Neurochem. 49: 1853-1862.

Willison, H. J., B. D. Trapp, J. D. Bacher, and R. H. Quarles (1988) The expression of myelin-associated glycoprotein during remyelination in cat sciatic nerve. Brain Res. 444: 10-16.

Wood, J. G., and E. L. Engel (1976) Peripheral nerve glycoproteins and myelin fine structure during development of the rat sciatic nerve. J. Neurocytol. 5: 605-615. 